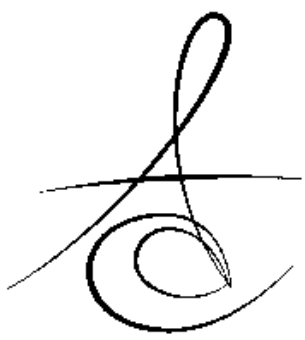

\section{EKTODERMAL DİSPLAZİLI ÇOCUK HASTADA DENTAL TEDAVİ YAKLAŞIMI: BİR OLGU RAPORU}

DENTAL TREATMENT APPROACH IN PEDIATRIC PATIENT WITH ECTODERMAL DYSPLASIA : A CASE REPORT

\author{
Yrd. Doç. Dr. Kenan CANTEKİN*
}

Arş. Gör. Ebru DELİKAN*

\section{ÖZET}

Ektodermal displazi diş, tırnak, saç, sinir hücreleri ve ter bezleri gibi embriyonik ektodermal kaynaklı yapıların iki veya daha fazlasında anormal gelişim ile ilişkili kalıtsal bir hastalıktır. Ektodermal displazi ter bezlerinin durumuna göre hidrotik ve anhidrotik/ hipohidrotik olarak ikiye ayrılırlar. Hipohidrotik tip X-bağlı resesif kalıtım gösterirken, hidrotik tip ise otozomal dominant kalıtım gösterir. Ektodermal displazinin en sık rastlanılan ağız bulgusu süt ve daimi dişlerdeki eksikliktir. Bu nedenle, etkilenen hastalara çoğunlukla gelişim yıllarında diş protez tedavileri yapılması önerilmektedir. $\mathrm{Bu}$ çalışmada hidrotik tip ektodermal displazi teşhisi konmuş, hipodonti ve onikodisplazi (displastik tırnak) gibi hastalığın tipik özelliklerini taşıyan bir olgunun ağız içi bulguları ve dental tedavi yaklaşımı sunulmuştur.

Anahtar kelimeler: Hidrotik Ektodermal displazi, hipodonti, otozomal dominant

\section{ABSTRACT}

Ectodermal dyplasia is a hereditary disease associated with abnormal development of two or more embryonic ectodermal structures such as teeth, nail, hair, nerve cells and sweat glands. According to the state of sweat glands involvement ectodermal dysplasia is divided into two major grups: hydrotic and hypohydrotic/ anhydrotic. As hypohydrotic type is inherited in X- linked mode, hydrotic type is inherited in autosomally dominant. The most common oral manifestation of ectodermal dysplasia is teeth deficiency in primary and/ or permenant dentition. Therefore, during the development of the child, protetic rehabilitations could be necessary. Hydrotic type of ectodermal dysplasia diagnosed case with the typical features of the diseas such as hypodontia and onycodysplasia is presented in this study in term of oral manifestation and dental treatment approach.

Keywords: Hydrotic ectodermal dysplasia, hypodontia, autosomal dominant

\section{GİRİŞ}

Kalıtsal ektodermal displazi iki veya daha fazla ektodermal kaynaklı anatomik yapının başarısız gelişiminin olduğu büyük bir grup hastalığı temsil eder. Ektodermal displazili (ED) hastalar cilt, saç, tırnak, diş, sinir hücreleri, ter bezleri, göz ve kulağın bazı bölümleri ve diğer organ yapılarının gelişmemesi veya az gelişimi ile karakterizedir. ${ }^{1}$

Ektodermal displazi otozomal dominant, otozomal resesif ve $\mathrm{X}$-bağlı resesif gibi çeşitli genetik modelde kalıtılabilir. ${ }^{2}$ Yüz yetmiş farklı alt tipi tespit edilmesine rağmen, bu hastalık 1/ 100.000 insidans oranı ile oldukça nadir olarak görülen bir hastalıktır. ${ }^{3}$ $\mathrm{Bu}$ hastalık ter bezlerinin tutulumu durumuna göre, iki ana gruba ayrılır: (1) Hipohidrotik ED / anhidrotik ED (Christ-Siemens-Touriane sendromu): Bu grupta ter bezleri ya yoktur ya da sayısı önemli ölçüde azalmıştır, (2) Hidrotik ED (Cloustone sendromu, diş- tırnak sendromu, Witkop Sendromu): Ter bezlerinin normal olduğu gruba verilen addır. Diş ve saçların tutulumu iki grupta da benzerdir fakat tırnak ve ter bezlerinin kalıtsal tutulum modelleri farklıdır. ${ }^{4,5}$

* Erciyes Üniversitesi, Çocuk Diş Hekimliği Bölümü ,Kayseri, 
Dişlerde sayıca belirgin azalma (oligodonti veya hipodonti) ve kesici şekillerinde sıklıkla anormal gelişim (sivri, konik) görülür. Molar dişlerin ise boyutlarında küçülmeye rastlanabilir. ${ }^{6}$ Ayrıca bu dişlerin tüberkülleri atipik görünümlü olabilir. Diş tomurcuğu oluşumu eksikliği alveoler kemikte hipoplaziye yol açar, bu durum da azalmış dikey boyuta sebep olur. Bu nedenle etkilenen bireylerde yaşlı yüz görünümü yaygındır. Ektodermal displazi çeşitli araştırmacılar tarafından farklı şekillerde sınıflandırılmıştır.

Freire- Maia, ektodermal bozuklukları 4 ana grupta toplamıştı: ${ }^{7}$

1- Hipohidrozis: Yağ ve ter bezlerinin olmaması veya az olması

2- Hipotrikozis: İnce ve seyrek saçlar, kaşların ve kirpiklerin yokluğu ile belirgindir.

3- Hipodonti: Anadonti ve daha sıklıkla oligodonti şeklinde görülür.

4- Onikodisplazi: Displazik tırnak teşekkülü şeklinde görülür.

Witkop tarafından yapılan sınıflandırmaya göre: ${ }^{8}$

Tip I: Yaygın şekilde görülen hipohidrotik tip, X- bağlı resesif geçiş gösterir.( Christ-SiemensTouriane sendromu) Ter bezlerinin gelişimi azdır veya hiç yoktur.

Tip II: Normal kaş ve saçlara sahip, hipodonti ve displastik tırnaklarla görülen hidrotik tip, otozomal dominant geçiş gösterir. (Cloustone sendromu, diştırnak sendromu, Witkop Sendromu)

Tip III: Dişlerin normal olduğu, özellikle saç ve tırnakları etkileyen, otozomal resesif, pençe formundaki hidrotik tip ( kondroektodermaldisplazi, Ellis- van Creveld Sendromu).

$\mathrm{Bu}$ makalede kalitsal hidrotik tip ED olan çocuk hastada erken karışık dişlenme döneminde yapılan ve gelecekte yapılması planlanan tedavi protokolü sunulmaktadır.

\section{OLGU RAPORU}

8 yaşındaki kız hasta dişlerde eksiklik şikâyeti ile Erciyes Üniversitesi Diş Hekimliği Fakültesi Pedodonti Anabilim Dalı kliniğine başvurdu. Yapılan ekstraoral muayeneye göre saç ve kirpikler normal, kaşlar ise seyrekti (Şekil 1). Terleme ile ilgili herhangi bir şikayeti bulunmazken, tırnaklarının kırıgan yapıda olduğu ve zor uzadığı öğrenildi. ( Şekil 2) Bu bulgular hidrotik ED'nin (diş- tırnak sendromu) tipik özellikleri ile uyumluydu. Ağız içi muayenede erken karışık dişlenme döneminde olan hastada üst çenede 52,54 , 62 ,64, alt çenede ise 72, 74, 82 olmak üzere toplamda 7 diş eksikliği olduğu belirlenmiştir. (Şekil 3) Ayrica panoramik radyografi incelemesi sonucunda 15 adet daimi diş eksiği $(12,13,14,15,22,23,24,25$, $31,32,33,34,41,42,43$ ) olduğu saptanmıştır (Şekil 4). Daha sonra ailesel olarak incelenen olgu sonuçlarına göre ikiz kız kardeşinde herhangi anormal bir dental bulguya rastlanmazken, 13 yaşındaki erkek kardeşte klinik ve radyografik inceleme sonucunda oligodonti mevcudiyeti saptanmıştır.

Erken karışık dişlenme döneminde olan hastanın ortodonti konsültasyonu sonrası posterior bölgede maksiller darlığa bağlı olarak oluşan çapraz kapanışın düzeltilmesi için ekspansiyon yapılmaya başlanmışıı. Hastamızın 16, 26, 55, 65, 75, 84,85 numaralı dişleri kompomer veya kompozit dolgularla restore edilmiş olup, psikolojik olarak rahatsızlık oluşturan konik şekilli 71 ve 81 numaralı dişler ise strip kronlarla şekillendirilmiştir (Şekil 5). Mevcut durum itibariyle diş arkında yeterinde boşluk bulunmadığından dolayı, protetik rehabilitasyon uygulaması yapılmamışıtır. Daimi dentisyonda sayıca çok fazla diş eksikliği olduğundan gelecek yıllarda hastamıza çocuk protezi, büyüme gelişim tamamlandıktan sonra ise implant destekli sabit protez yapılabileceği düşünülmektedir. Hastaya ve ailesine, ağız hijyeninin korunması için gerekli bilgiler verilmiş olup, 6 aylık periyotlar halinde kontrollere gelmeleri tavsiye edilmiştir.

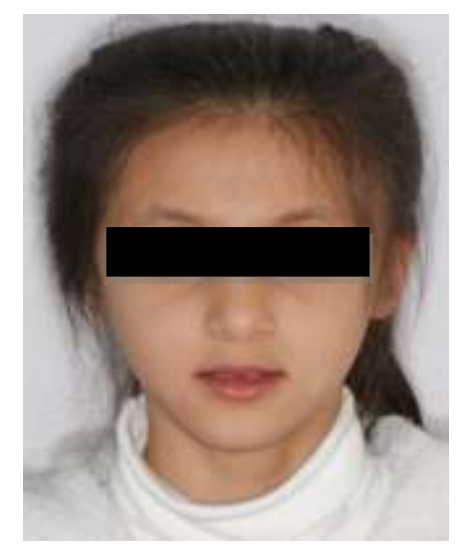

Şekil 1. Hastanın cepheden alınan fotoğrafı 


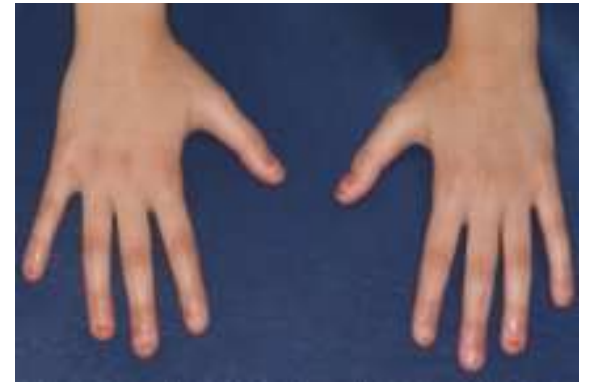

Şekil 2. Hastanın el ve tırnak fotoğrafı

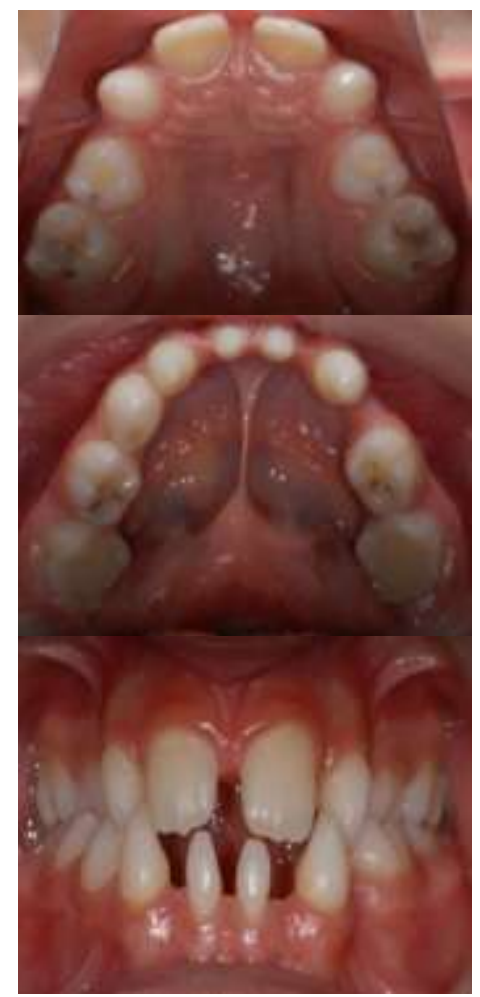

$\mathbf{a}$

b

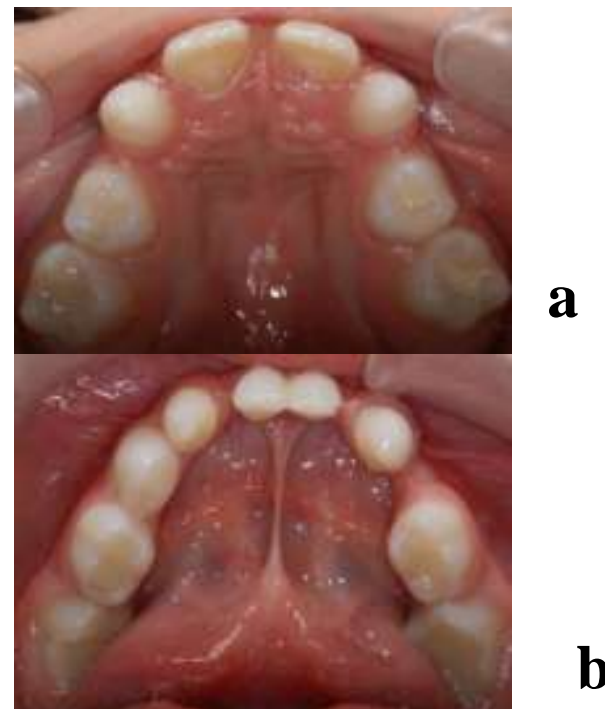

Şekil 3. a)üst çene fotoğrafı b) alt çene fotoğrafı c) ağız içi cepheden fotoğraf

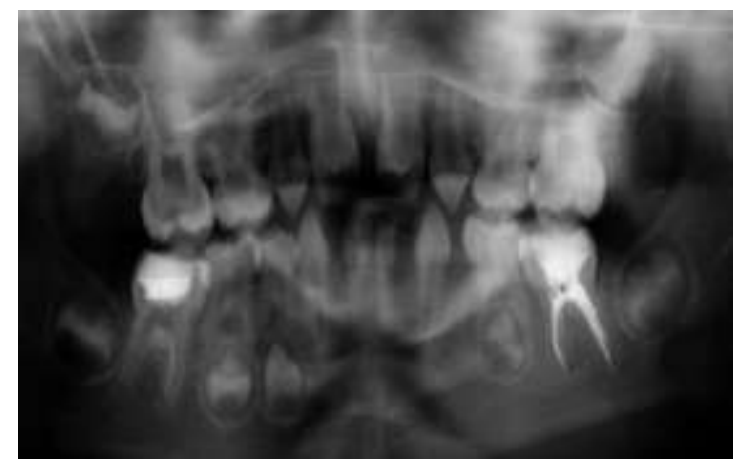

Şekil 4. Hastanın teşhis için alınan panoramik filmi

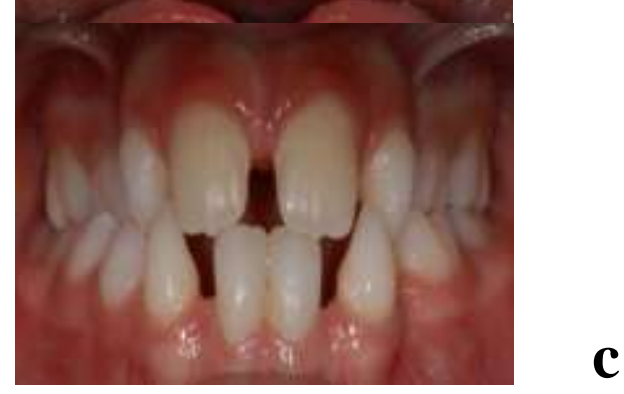

Şekil 5. Tedavi sonrası a) üst çene fotoğrafı b) alt çene fotoğrafı c) ağız içi cepheden fotoğraf

\section{TARTIŞMA}

Ektodermal displazi hastalarında diş tedavileri, kraniofasiyal büyüme ve gelişim döneminde vertikal ve sagital iskeletsel ilişkilerin kurulması, estetik, konuşma ve çiğneme yeterliliğinin sağlanması için önemlidir. ${ }^{4}$ Ağızda bulunan dişler koruyucu ve restoratif tedaviler ile korunmalıdır. Bu dişler yapılacak protezlerin tutuculuğu ve stabilizasyonunda büyük önem taşırlar. Ektodermal displazi hastalarının protetik tedavisinde değişik tiplerde protezler uygulandığı görülmektedir. Tedavi sabit, hareketli, tam ve implant destekli protezleri içermektedir. ${ }^{4,9-11}$ Protezlerin olumlu etkileri arasında daha fazla kendine güven, yüz estetiği, konuşma ve çiğneme fonksiyonunda artış sayılabilir. ${ }^{12}$

En yaygın uygulanan tedavi şekli çocuk protezidir. Erken protetik tedavi genellikle 5 yaşından itibaren tavsiye edilir. Çocuğun uyumuna bağlı olarak 3- 4 yaşında da protez yapılabilir. ${ }^{12}$ Fakat çocuk psikolojik ve zihinsel olarak bu tedaviyi kabul

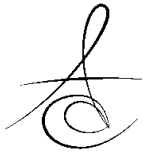


edebilecek düzeyde olmalıdır. 2,4,13 Ancak hareketli parsiyel veya tam protezler düzenli kontroller gerektirir. Büyümeye bağlı olarak dikey boyutta azalma ve anormal alt çene postürü tespit edildiğinde protezin yenilenmesi gereklidir. ${ }^{14}$ Protezlerde tutuculuk ve stabilitenin sağlanması zordur. Ektodermal displazili hastalarda kuru ağız mukozası, az gelişmiş maksiller tüber ve alveol sırtları protezde tutuculuk ve stabilitenin sağlanmasını zorlaştıran faktörlerdir. ${ }^{15} \mathrm{Bu}$ hastalarda protez yapımı sırasında protez kaidesini mümkün olduğunca uzatarak okluzal yükleri daha geniş bir alana dağıtmaya dikkat edilmelidir. Atipik konik kesici dişler hareketli parsiyel protezin stabilizasyonu için uygun olmasa da bu dişler overdenture protezler altında abutment (destek) olarak kullanılabilirler. ${ }^{16}$

İmplant destekli protezler, 12 yaş üzeri gençlerde ideal rekonstrüksiyon (yeniden yapılandırma) yöntemi olarak önerilmektedir. ${ }^{17}$ Büyüme ve gelişimini tamamlamış $E D$ hastalarında implantlar protezi destekleme, stabilize etme ve tutuculuğu arttırma amaçlı kullanılabilirler. Ayrıca implant tedavisi bazı durumlarda alveol kemiğinin rezorpsiyondan korunmasına da yardımcı olabilir. ${ }^{17}$ Fakat implant tedavisinde zaten alveol yetersizliği olan bu hastalarda bir de kemik atrofisi varsa, en büyük problem yetersiz kemik miktarı olmaktadır. Bu durumlarda implant yerleşimi kemik grefti olmadan mümkün olmamaktadır. ${ }^{17}$ İmplant cerrahisi konservatif protetik tedavi ile karşılaştıııldığında, küçük çocuklardaki olumsuz psikolojik etkisinin yanı sıra, daha yüksek başarısızlık intimaline de sahiptir. ${ }^{18-20}$ Büyümesi devam eden bir çocukta erken implant yerleşimi, implantın ankiloz dişe benzer davranışı sonucu bazı kozmetik sorunlara yol açar. Kraniofasiyal gelişim boyunca implant üstü yapılar karşıt dişlerle okluzyona gelmeyebilir ve hatta komşu dişler boşluğa doğru eğilebilir. Bu nedenle küçük çocuklarda implantların kullanımında dikkatli olunmalıdır.

Kısmi diş eksikliği veya tam dişsizlik alveol sırtlarında atrofiye, dikey boyutta azalmaya, çene belirginleşmesine ve sınıf III ilişkiye neden olabildiği için mümkün olduğunca erken protetik tedavi yapılmalıdır. Bu tedavi hastanın yaşam kalitesini artııır ve fonksiyonel ve estetik rehabilitasyon (onarım) için kabul edilebilir bir tedavi yöntemi olarak değerlendirilebilir.

\section{SONUÇ}

Klinikte, diş eksikliği pek sık rastlanılan bir durum değildir. Diş eksikliği varlığı durumunda (özellikle oligodonti) ekstraoral veya intraoral başka patolojik bulgu olup olmadığı iyi değerlendirilmelidir. Diş hekimleri özellikle de pedodontistler ED'nin karakteristik özelliklerini iyi bilmeli ve karşılaştıklarında erken teşhis edebilmelidirler. Ektodermal displazili hastalarda çoğunlukla multidisipliner tedaviye gereksinim duyulur. Pedodonti uzmanı, ortodonti uzmanı, cerrah, protez uzmanı ve psikiyatri uzmanlarının ortak değerlendirmeleri sonucu tedavi planlaması yapılması önerilir. Ancak uzun vadede başarı, düzenli kontrol randevuları ve ağız hijyeninin tam yapılmasına bağlıdır.

\section{KAYNAKLAR}

1. Lee CA, Damm DD, Neville BW, Allen C. Oral and maxillofacial pathology. 2008;741-2

2. Hickey AJ, Vergo TJ, Jr. Prosthetic treatments for patients with ectodermal dysplasia. J Prosthet Dent 2001;86:364-8.

3. Vieira KA, Teixeira MS, Guirado CG, Gaviao MB. Prosthodontic treatment of hypohidrotic ectodermal dysplasia with complete anodontia: case report. Quintessence Int 2007;38:75-80.

4. Tarjan I, Gabris K, Rozsa N. Early prosthetic treatment of patients with ectodermal dysplasia: a clinical report. J Prosthet Dent 2005;93:419-24.

5. Nunn JH, Carter NE, Gillgrass TJ, Hobson RS, Jepson NJ, Meechan JG et al. The interdisciplinary management of hypodontia: background and role of paediatric dentistry. Br Dent J 2003;194:245-51.

6. Kearns G, Sharma A, Perrott D, Schmidt B, Kaban L, Vargervik K. Placement of endosseous implants in children and adolescents with hereditary ectodermal dysplasia. Oral Surg Oral Med Oral Pathol Oral Radiol Endod 1999;88:5-10.

7. Freire-Maia N. Ectodermal dysplasias. Hum Hered 1971;21:309-12.

8. CJ W. Oral Pathology. New York: McGraw-Hill; 1965.

9. Pigno MA, Blackman RB, Cronin RJ, Jr., Cavazos E. Prosthodontic management of ectodermal dysplasia: a review of the literature. J Prosthet Dent 1996;76:541-5. 
10. NaBadalung DP. Prosthodontic rehabilitation of an anhidrotic ectodermal dysplasia patient: a clinical report. J Prosthet Dent 1999;81:499-502.

11. Imirzalioglu P, Uckan S, Haydar SG. Surgical and prosthodontic treatment alternatives for children and adolescents with ectodermal dysplasia: a clinical report. J Prosthet Dent 2002;88:569-72.

12. Ramos V, Giebink DL, Fisher JG, Christensen LC. Complete dentures for a child with hypohidrotic ectodermal dysplasia: a clinical report. J Prosthet Dent 1995;74:329-31.

13. Yavuz I, Baskan Z, Ulku R, Dulgergil TC, Dari O, Ece $A$ et al. Ectodermal dysplasia: Retrospective study of fifteen cases. Arch Med Res 2006;37:4039.

14. Franchi L, Branchi R, Tollaro I. Craniofacial changes following early prosthetic treatment in a case of hypohidrotic ectodermal dysplasia with complete anodontia. ASDC J Dent Child 1998;65:116-21.

15. Shaw RM. Prosthetic management of hypohydrotic ectodermal dysplasia with anodontia. Case report. Aust Dent J 1990;35:113-6.

16. O'Dwyer MR, Renner RP, Fergusen FS. Overdenture treatment--one aspect of the team approach for the EEC syndrome patient. J Pedod 1984;8:192-205.

17. Hekmatfar S, Jafari K, Meshki R, Badakhsh S. Dental management of ectodermal dysplasia: two clinical case reports. J Dent Res Dent Clin Dent Prospects 2012;6:108-12.

18. Lo Muzio L, Bucci P, Carile F, Riccitiello F, Scotti C, Coccia $E$ et al. Prosthetic rehabilitation of a child affected from anhydrotic ectodermal dysplasia: a case report. J Contemp Dent Pract 2005;6:120-6.

19. Rad AS, Siadat H, Monzavi A, Mangoli AA. Full mouth rehabilitation of a hypohidrotic ectodermal dysplasia patient with dental implants: a clinical report. J Prosthodont 2007;16:209-13.

20. Başkan Ülkü SZ, Yavuz İ. Ektodermal displazili hastalarda protetik yaklaşımlar. Atatürk Üniv Diş Hek Fak Derg 2001:21: 57-61.

\section{Yazışma Adresi}

Dr. Kenan Cantekin, Erciyes Üniversitesi Diş Hekimliği Fakültesi Çocuk Diş Hekimliği Anabilim Dalı, Kayseri, 38039, Türkiye Tlf: +90. (352) 20766 66-29254 Fax numarası: +90 352- 4380657

E-mail adresi: k_cantekin@hotmail.com 